\title{
Akılı Hava İstasyonu ile IoT Tabanlı Hava Durumu İzleme Sistemi
}

\author{
Hakan Üçgün ${ }^{*}$, Zeynep Kübra Kaplan², Uğur Yüzgeç³ \\ 1* Bilecik Şeyh Edebali Üniversitesi, Bilgi İşlem Daire Başkanlığı, Bilecik, Türkiye (ORCID: 0000-0002-9448-0679) \\ hakan.ucgun@bilecik.edu.tr \\ 2 Bilecik Şeyh Edebali Üniversitesi, Mühendislik Fakültesi, Bilgisayar Mühendisliği Bölümü, Bilecik, Türkiye (ORCID: 0000-0002-8154-2535) \\ zeynepkubrakaplan05@gmail.com \\ ${ }^{3}$ Bilecik Şeyh Edebali Üniversitesi, Mühendislik Fakültesi, Bilgisayar Mühendisliği Bölümü, Bilecik, Türkiye (ORCID: 0000-0002-5364-6265) \\ ugur.yuzgec@bilecik.edu.tr
}

(İlk Geliş Tarihi 24 Şubat 2021 ve Kabul Tarihi 9 Nisan 2021)

(DOI: $10.31590 /$ ejosat.886025)

ATIF/REFERENCE: Üçgün, H., Kaplan, Z.K., \& Yüzgeç, U., (2021). Akıllı Hava İstasyonu ile IoT Tabanlı Hava Durumu İzleme Sistemi. European Journal of Science and Technology, (21), 563-571.

\section{$\ddot{O} \mathbf{z}$}

İklim koşullarında meydana gelen değişiklikler, küresel ısınma ile birlikte ortaya çıkan ve insan hayatını pek çok yönden olumsuz olarak etkileyen problemlerdendir. Hava durumunda meydana gelen ani değişiklikler yüzünden sel, heyelan, firtına gibi doğal afetler meydana gelmekte, can ve mal kayıpları yaşanmaktadır. Bu nedenle hava durumundaki değişikliklerin ve hava koşullarının doğru bir şekilde tespit edilmesi ve takip edilmesi büyük önem arz etmektedir. Bir yerin ya da bölgenin hava koşulları hakkında veri toplamak amacıyla hava istasyonları kullanılmaktadır. Bu çalışma kapsamında IoT tabanlı düşük maliyetli bir hava durumu izleme sistemi gerçekleştirilmiştir. Sistem içerisinde Raspberry Pi 3 kontrolcü kartı, sıcaklık, nem, basınç, yağmur, rüzgâr hızı ve rüzgâr yönü sensörleri kullanılmıştır. Sensörlerden alınan analog ve dijital veriler işlenerek hava durumu ile ilgili değerler elde edilmiştir. Hazırlanan web arayüzü aracılı̆̆ıyla internet üzerinden hava durumu verileri izlenmektedir. Gerçekleştirilen hava istasyonunun mobil platform şeklinde tasarlanması, herhangi bir bölgedeki hava durumunun izlenmesi için kullanılabilmesine imkân sağlamaktadır. İstasyon ile hava durumunun izlenmesinin yanı sıra sensörlerden elde edilen veriler kullanılarak hava durumunun tahmin edilmesi de sağlanmıştır.

Anahtar Kelimeler: Hava İstasyonu, Hava Durumunun İzlenmesi, IoT, Raspberry Pi, Sensör Sistemleri.

\section{IoT Based Weather Monitoring System with Smart Weather Station}

\begin{abstract}
Changes in climatic conditions are problems that arise with global warming and affect human life in many ways. Due to sudden changes in weather conditions, natural disasters may occur such as floods, landslides, storms and loss of life and property may experience. Therefore, it is very important to accurately detect and monitoring weather condition changes and weather conditions. Weather stations are used to collect data about the weather conditions of a place or region. In this study, IoT based a low cost weather condition monitoring system has been realized. Raspberry Pi 3 controller card, temperature, humidity, pressure, rain, wind speed and wind direction sensors are used in the system. Analog and digital data received from the sensors were processed to obtain weather condition values. Weather condition information is monitored via the web interface. The design of the realized weather station in the form of a mobile platform allows it to be used for monitoring of weather condition in any region. In addition to monitoring the weather condition with the station, it was provided to estimate the weather condition by using the data obtained from the sensors.
\end{abstract}

Keywords: Weather Station, Weather Forecast Monitoring, IoT, Raspberry Pi, Sensor Systems.

*Sorumlu Yazar: hakan.ucgun@ bilecik.edu.tr 


\section{Giriş}

İklim koşulları, dünya üzerindeki bütün insanların sağlığını ve günlük yaşamın aktivitelerini etkileyen önemli faktörlerden birisidir (Aponte-Roa ve ark., 2018). İklim koşullarındaki dengesizlikler, insanların hayatını olumsuz etkilemektedir.

İklim koşullarındaki dengesizlikler, insanların hayatını olumsuz etkilemektedir. Son yıllarda pek çok yerde görülen mevsim dengesizlikleri, insanlar için büyük bir tehlike arz etmektedir. Hava durumundaki değişiklikler, can ve mal kayıplarına sebebiyet verebilmektedir (Fente ve Singh, 2018). Ülkemizde de yakın dönemde meydana gelen yağış ve sel felaketleri yüzünden can ve mal kayıpları yaşanmıştır. Önceki yıllarda, aylar içerisinde değişmekte olan hava koşulları, günümüzde gün içerisinde değişebilmektedir (Nsabagwa ve ark., 2019). Hava durumunun elektronik ve izleme teknolojilerini kullanarak tahmin edilmesi veya izlenmesi ile meydana gelebilecek sorunları ortadan kaldırmak mümkündür. Bu amaçlar doğrultusunda hava tahmin ve izleme istasyonları geliştirilmektedir.

Günümüz teknolojileri arasında yer edinmiş ve pek çok uygulama alanında araştırma ve geliştirme faaliyetleri devam eden nesnelerin interneti (Internet of Things, IoT) teknolojisi, temel olarak gerçek dünya nesnelerinin farklı teknolojiler aracılığıyla internet üzerinden haberleşmesini sağlamaktadır. Başka bir deyişle IoT, gerçek dünyayı internete bağlamak için kullanılmaktadır (Eriş ve Bölük, 2020). IoT sistemlerinde genel olarak sensörler, aktüatörler, akıllı cihazlar gibi donanımlar bulunmaktadır. IoT tabanlı uygulamalarda, sistemlerin uzaktan kontrolü, takibi ve çalıştırılmasına yönelik uygulamalar yapılmaktadır.

\section{Literatür Araștırması}

Hava tahmini, belirli saatlerde herhangi bir yerde görülebilecek meteorolojik olayları, gözlem ve analizlere dayalı nesnel ve öznel yöntemler kullanarak önceden tespit etme işlemidir. Hava durumunun tahmin edilmesi sırasında gözlem, analiz ve tahmin olmak üzere 3 işlem gerçekleştirilir (Üçgün ve Kaplan, 2017). Hava durumunun tahmin edilmesi için kapsamlı meteorolojik veriler gerekmektir. Var olan meteorolojik veri toplama araçlarının maliyetlerinin yüksek olması kapsamlı izleme konusunda bazı dezavantajlara yol açmaktadır (Saini ve ark., 2016). Bu durumdan kurtulmak için düşük maliyetli mini hava istasyonları yapılmaktadır. Hava istasyonları, hava durumundaki değişiklikleri gözlemlemek ve elde ettiği verileri belirlenen yerlere göndermek için kullanılan meteorolojik istasyonlardır. Modern hava izleme istasyonlarında, sıcaklık, bağıl nem, çiğ noktası, rüzgâr yönü, rüzgâr hızı, atmosfer basıncı gibi hava parametrelerinde meydana gelen değişiklikleri izlemek amacıyla çeşitli sensörler kullanılmaktadır. Meteorolojik sensörlerin bir mikrodenetleyici aracılığıyla kontrol edilmesi ile hava ölçümleri, otomatik olarak kolay ve ucuz bir şekilde yapılmaktadır. $\mathrm{Bu}$ sayede hava izleme sistemlerinin maliyetleri en aza indirgenebilir (Devaraju ve ark., 2015).

Yapılan çalışmalara bakılırsa, Devaraju ve arkadaşları (Devaraju ve ark., 2015), PIC16F887 mikrodenetleyicisi kullanarak düşük maliyetli, kablosuz ve taşınabilir bir hava izleme istasyonu gerçekleştirmişler. İstasyon ile bağıl nem, atmosfer basınc1, yağış, güneş radyasyonu, rüzgâr hızı, rüzgâr yönü, yüzey ve ortam sicaklığı gibi hava parametreleri ölçülmektedir. Ölçülen hava parametreleri hem kaydedilmekte, hem de kablolu ve kablosuz modüller aracılığıyla kullanıcılara aktarılmaktadır. Hussein ve arkadaşları (Hussein ve ark., 2020), Arduino Uno ve ZigBee teknolojisi kullanarak düşük maliyetli hava istasyonu prototipi oluşturmuşlardı. Yağmur durumu, rüzgâr seviyesi, hava basıncı, toz yoğunluğu, sıcaklık ve nem gibi parametreler, sensörler ile belirlenmektedir. Veriler, birden fazla verici düğümden alınarak bir SD kart içerisine tarih ve saat bilgileri de eklenerek kaydedilmektedir. İstasyon ile ölçülen değerler, www.weather.com sitesi üzerinden alınan sonuçlarla karşılaştırılmış önerilen modelin herhangi bir alanda internet bağlantısı olmadan güvenilir bir şekilde uygulanabileceği kanıtlanmıştır. Muck ve arkadaşları (Muck ve Homam, 2018), Arduino Uno, Raspberry Pi 3, SparkFun Weather Shield ve Weather Meter kullanarak bir yerin gerçek zamanlı hava parametrelerinin çevrimiçi takip edilebileceği bir hava sistemi oluşturmuşlardır. Sensörler aracılığıyla toplanan veriler, Google Cloud SQL'de depolanmakta ve hava durumu verilerinin analizi yapılmaktadır. Mobil ve web tabanlı gerçekleştirilen arayüzler ile gerçek zamanlı hava durumu bilgileri görsel olarak kullanıcılara sunulmuştur. Kullanıcılara hava durumu ile ilgili bildirimler verilmektedir. Baste ve arkadaşları (Baste ve Dighe, 2017), okullarda ve araştırma merkezlerinde gerçek zamanlı hava durumunun izlenmesi için düşük maliyetli ve küçük boyutlu bir hava istasyonu geliştirmişlerdir. Rüzgâr hızı, rüzgâr yönü, hava sıcaklığı, nem, atmosferik basınç, yağmur ve güneş radyasyonu verileri, Raspberry Pi 3 Kontrolcü kartı aracılığıyla Wi-Fi ağı ile veri tabanı sunucusuna aktarılmaktadır. Bu verilere, web sayfası üzerinden uzaktan erişim sağlanarak hava durumu bilgilerini kullanıcıların görmesi sağlanmaktadır. Ram ve arkadaşları (Ram ve Gupta, 2016), ARM tabanlı LPC2148 mikrodenetleyicisi ve wi-fi modülü aracılığıyla belirli bir yerdeki hava koşullarını izlemek için internet üzerinden erişilebilir bir sistem geliştirmişlerdir. Sistemde sıcaklık, bağıl nem, 1ş1k yoğunluğu ve $\mathrm{CO} 2$ seviyesi gibi çevresel koşullar, sensörler ile izlenmekte ve kontrol edilmektedir. Sensör bilgileri, Thingspeak sunucusuna gönderilerek kullanıcılara gösterilen grafikler elde edilmektedir. Sensör verileri 15 saniyede bir güncellenmektedir. Tablo 1'de, literatür taraması sonucunda elde edilen çalışmaların karşılaştırmalı analizi verilmiştir. Katyal ve arkadaşları (Katyal ve ark., 2016), Arduino tabanlı web üzerinden canlı hava durumu sonuçlarını gösterebilen düşük maliyetli bir hava istasyonu geliştirmişlerdir. İstasyon ile sıcaklık, nem, 1şık şiddeti, basınç, yağmur verileri ölçülmektedir. Haque ve arkadaşları (Haque ve ark., 2019), hava parametrelerinin izlenebilmesi için kullanılacak yenilenebilir enerji destekli bir hava istasyonu geliştirmişlerdir. Hava istasyonu ile sicaklık, nem, yağmur damlası, karbon monoksit, duman, ortamdaki LPG, barometrik basınç, rakım gibi parametre verileri takip edilmektedir. Sistem içerisindeki GSM sensörü yardımıyla hava durumu ile ilgili bilgiler kullanıcıya SMS olarak gönderilmektedir. Hava istasyonu verileri, ulusal hava durumu verileri karşılaştırılmış. Karşılaştırmalar sonucu sıcaklıkta \% 1, nemde için \% 5 ve barometrik basınçta \% 8'lik bir sapma değeri saptanmıştır. Kusriyanto ve arkadaşları (Kusriyanto ve Putra, 2018), IoT platformu kullanılarak web sitesi üzerinden erişilebilen hava durumu istasyonu geliştirmişlerdir. Kullanıcılar, bölgeye gitmeden o bölgedeki hava değişikliklerini takip edebilmektedir. Arduino Mega 2560 kontrolcü kartının kullanıldığı sistemde, sıcaklı, nem, basınç ve yağmur verileri ölçülmektedir. Hava durumu tahmini için hava basıncı verileri kullanılmıştır. Tüm sensörlerin ölçüm sonuçları SD Kartta depolanmış ve TFT ekran üzerinde ESP8266 wifi modülü kullanılarak web sitesinde görüntülenmektedir. Li ve arkadaşları 
(Li ve ark., 2017), araştırmacıların kısa vadede düşük fiyata büyük miktarda meteorolojik bilgi almasını mümkün kılan mikro otomatik hava durumu istasyonu geliştirmişlerdir. STM32 kartı ile rüzgar hızı, rüzgar yönü, ışık yoğunluğu, ortam sıcaklığının ve neminin izlendiği sistemde GPS üzerinden alınan coğrafi bilgilerle birlikte tüm gerçek zamanlı meteorolojik veriler kablosuz GPRS ağ1 üzerinden baz istasyonuna gönderilmiş ve ağa bağlı veriler, sunucuda analiz edilmiştir.

Tablo 1. Hava İstasyonlarının Karşılaştırmalı Analizi

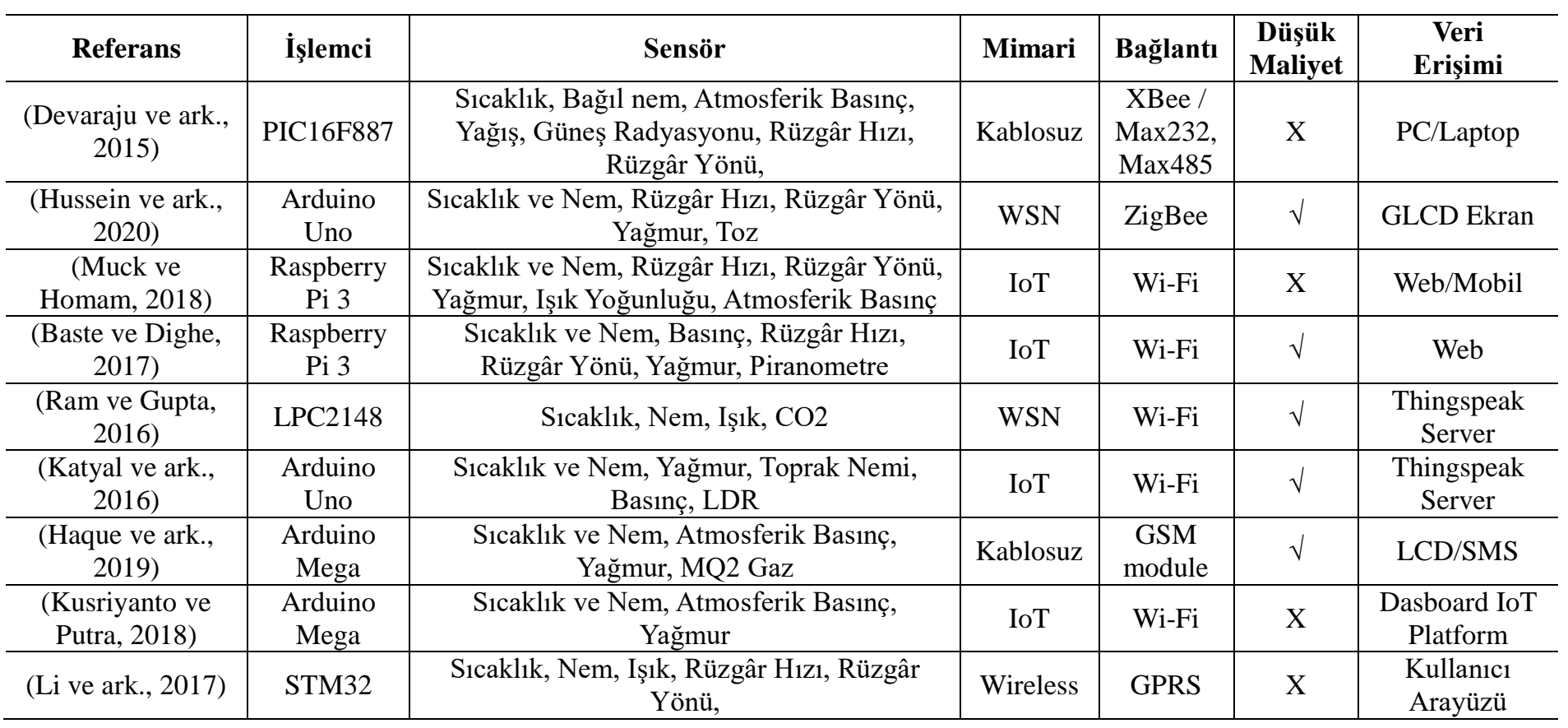

\section{Hava Durumu İstasyonunun Tasarımı}

IoT tabanlı hava durumu izleme sisteminin içerisinde donanımsal olarak Raspberry Pi 3 kartı, sıcaklık ve nem, basınç, yağmur, rüzgâr hızı ve rüzgâr yönü sensörleri kullanılmıştır. Yazılımsal olarak ise python ve php programlama dilleri ve mysql veri tabanı kullanılmıştır. Sistemin blok diyagramı Şekil 1 'de verilmiştir. Sistem 2 adımda çalışmaktadır. İlk adımda, sensörler üzerinden alınan analog ve dijital veriler Raspberry Pi kontrolcü kartında işlenmekte ve işlenen veriler üzerinden hava durumu ile ilgili bilgiler çıkartılmaktadır. Sensörlerden elde edilen bilgiler hazırlanan veri tabanına kaydedilmektedir. İkinci aşamada veri tabanındaki bilgilerin kullanılmasıyla web arayüzü üzerinden hava durumu ile ilgili bilgiler izlenmesi sağlanmaktadır. Kısaca sistemde, ilk aşamada donanımsal olarak veriler elde edilmekte, ikinci aşamada kullanıcıların hava durumu bilgilerini görmesi sağlanmaktadır.

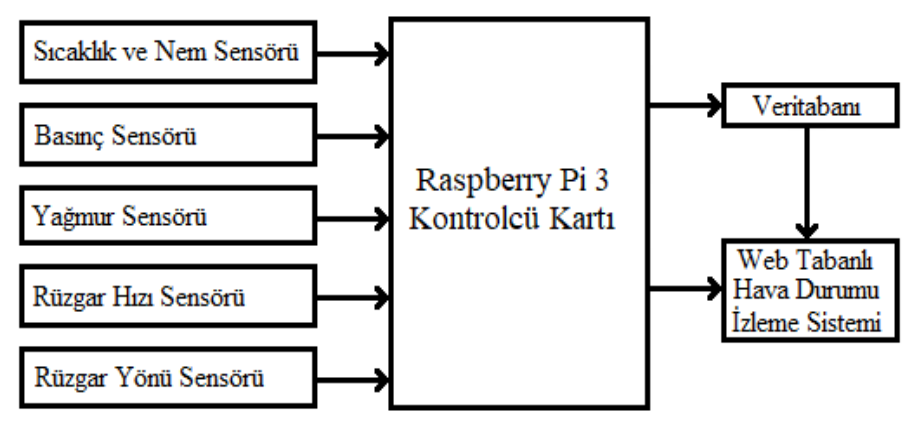

Şekil 1. Hava Durumu İzleme Sisteminin Blok Diyagramı

\subsection{Raspberry Pi 3 Kontrolcü Kartı}

Tek kart bir bilgisayar olarak bilinen Raspberry Pi kartları, bilgisayar biliminin gelişmesi amacıyla kar amacı gütmeyen Birleşik Krallık'taki Raspberry Pi Vakfı tarafından geliştirilmektedir. Raspberry $\mathrm{Pi}$ serinin 3.nesil ürünü olan Raspberry Pi 3 kartı, içerisinde barındırdığı dâhili Wi-Fi ve bluetooth teknolojileri sayesinde önceki sürümlerine göre büyük avantajlar sağlamaktadır. Bu özellikleri günümüzde IoT tabanlı uygulamalarda sıkça kullanılmaktadırlar. Raspberry Pi 3 kartı, 1.2 GHz ARM tabanlı cortex A-53 işlemcisi ve 1 GB DDR2 ram ile alternatifi olan diğer kontrolcülere kıyasla çok hızlı işlemler gerçekleştirebilmektedir. C, Python gibi gömülü sistem programlama dilleri ile programlanabilen kart içerisine Linux ve Windows işletim sistemleri kurulabilmektedir. GPIO pinleri sayesinde I2C, SPI, UART vb. seri iletişim protokollerini desteklemektedir (Sağlam ve ark., 2020). Çalışma kapsamında Raspbian işletim sistemi, phpmyadmin ve mysql server uygulamaları kurulmuştur.

\subsection{Sicaklık ve Nem Sensörü}

İç ve diş ortamlara ait nem ve sıcaklık değerlerinin ölçülmesinde kullanılan DHT11 sıcaklık ve nem sensörü, yüksek performanslı 8 bit mikrodenetleyici ile entegre edilmiştir. DHT11 sensörü, ntc sıcaklık ölçüm birimi ile sıcaklık değerini ölçmekte, resistif nem ölçüm birimi ile de nem değerini ölçmektedir. Ölçümlerin doğru yapılabilmesi için sensör ve kontrolcü kartı arasındaki yapılandırmaların uygun şekilde kalibre edilmesi gerekmektedir (Divya ve ark., 2020). Sensör, sıcaklık ölçümü yaparken 0 ile $50^{\circ} \mathrm{C}$ arasında $2^{\circ} \mathrm{C}$ hata payı, nem ölçümü yaparken ise $20-90 \% \mathrm{RH}$ arasında $5 \% \mathrm{RH}$ hata payı gösterebilmektedir. Sensör üzerinde 3 adet pin bulunmaktadır. Şekil 2.a'da DHT11 sıcaklık ve nem sensörü verilmiştir. 


\subsection{Basınç Sensörü}

Barometrik basınç sensörü olan BMP180, etraflarındaki havanın mutlak basıncını, yüksekliği ve sıcaklığı ölçebilmektedir. BMP180 basınç sensörü, robotik ve elektronik uygulamalarında hava basıncını ölçmek için kullanılan ve küçük boyutlara sahip olan bir sensördür. Ölçülen basınç hem hava durumuna hem de irtifaya göre değişebilir. Sensör ile 300-1100 $\mathrm{hPa}$ arasındaki basınç değerleri ve 500-9000 metre arasındaki yükseklik değerleri ölçülebilmektedir. $\mathrm{I}^{2} \mathrm{C}$ seri iletişim protokolü ile çalışan sensör, üzerinde "Besleme", "Toprak", "SCL (SerialClock)" ve "SDA (Serial Data)" pini olmak üzere toplam 4 pin bulundurmaktadır (Mahbub, 2020). Şekil 2.b'de BMP180 sensörü verilmiştir.

\subsection{Yağmur Sensörü}

Yağmur sensörü, analog veya dijital olarak çalışabilen, yağmurun tespit edilmesini veya yağmur şiddetinin ölçülebilmesini sağlayan bir sensördür. Sensör, yağmur algılama modülü ve sürücü devre kartı olmak üzere 2 parçadan oluşmaktadır. Algılama modülü, paralel sıralar halinde oluşturulan iletken çizgilerin su ile teması halinde, çıkışında analog ya da dijital değerler üretmektedir. Elde edilen değerler sürücü kartı ile değerlendirilerek tespit işlemleri gerçekleştirilmektedir (Barkunan ve ark., 2019). Sürücü kartı üzerinde bulunan potansiyometre ile sensörü hassasiyet değeri ayarlanmaktadır. Sensör üzerinde "Besleme", "Toprak" ve "Dijital Çıkış" pini olmak üzere 3 adet pin bulunmaktadır. Şekil 2.c'de yağmur sensörü verilmiştir.

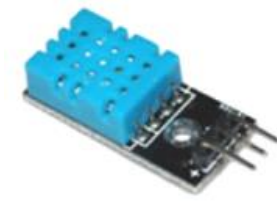

(a)

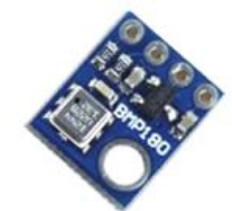

(b)

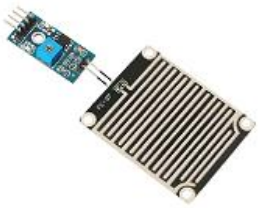

(c)
Şekil 2. Sensörler (a.DHT11 Sensörü, b. Basınç Sensörü c. Yağmur Sensörü)

\subsection{Rüzgâr Hızı Sensörü}

Çalışma kapsamında rüzgâr hızının ölçülmesi için özgün bir anemometre tasarımı yapılmıştır. Şekil 3.a'da tasarlanan anemometre/rüzgâr hızı sensörü verilmiştir. Sensör hazırlanırken rüzgârgülü sisteminin çalışma yapısı ele alınmıştır. Sensör, birbiri üzerine çapraz olarak geçirilmiş iki kol ve bu kolların etrafına sabitlenen dört adet yarım küre şeklindeki pinpon topu ile alt kısmında bulunan DC motordan oluşmaktadır. Sensörün şu şekilde çalışmaktadır; pinpon toplarına uygulanan rüzgâr şiddeti ile sensör çerçevesi, saat yönünde veya saatin tersi yönünde dönmektedir (Şekil 3.b). Rüzgârın hızına bağlı olarak, motorun şaftı dönerek bir hız değeri elde edilmekte ve DC motor ile çerçevenin dönüş hızı analog bir veri olarak tespit edilmektedir. Elde edilen analog veri ile oransal bir rüzgâr hızı belirlenir (Kishorebabu ve Sravanthi, 2020). Elde edilen hız verisinin Raspberry Pi 3 kontrolcü kartı üzerinden işlenebilmesi için analog değerin dijitale dönüştürülmesi gerekmektedir. $\mathrm{Bu}$ nedenle, Şekil 3.c'de gösterilen ADC click kartı kullanılmıştır. ADC click kartı girişine uygulanan analog değerleri dijitale çevirmek için kullanılan bir karttır. Motordan alınan analog değerler ADC click kartı ile dijital değerlere çevrilerek Raspberry $\mathrm{Pi} 3$ kontrolcü kartında işlenmektedir. $\mathrm{Bu}$ aşamalardan sonra rüzgâr hızı tespit edilmektedir.

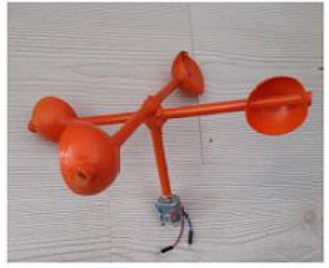

(a)

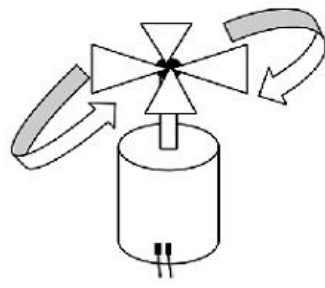

(b)

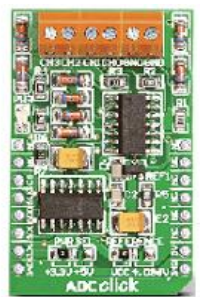

(c)

\section{Şekil 3. a. Gerçekleştirilen Rüzgâr Hızı Sensörü, b. Motor Dönüş Yönleri, c. ADC Click Kartı}

\subsection{Rüzgâr Yönü Sensörü}

Rüzgâr ölçümleri yapılan bölge, şehir, kasaba gibi yerlerde rüzgârlar, rutin bir şekilde belirli yönlerden esebileceği gibi değişik yönlerden de esebilirler. Bu bağlamda değişen rüzgâr yönlerinin belirlenmesi hava istasyonları için önem arz etmektedir. Rüzgâr yönü sensörleri, rüzgârın yönünü ölçen ve rüzgâr enerjisine dayalı olarak çalışabilen cihazlardır. $\mathrm{Bu}$ sensörlerde pervaneler bulunmazken bunun yerine dikey eksen üzerine dönen bir ok düzeneği kullanılmaktadır (Utama ve ark., 2018). Çalışma kapsamında rüzgâr yönünün belirlenebilmesi için özgün tasarıma sahip bir rüzgâr yönü sensörü yapılmıştır. Şekil 4.a'da hazırlanan rüzgâr yönü sensör verilmiştir. Sensör içerisinde HMC5883L pusula sensörü (Şekil 4.b) bulunmaktadır. Rüzgârın yönünü hesaplama için mavi renkli kartonlar ile ok şeklinde bir yapı tasarlanmıştır. Pusula sensörü üzerinden $0^{\circ}$ $360^{\circ}$ arasındaki açı değerleri elde edilmektedir. Elde edilen açı değerleri Şekil 4.c'de verilen rüzgâr açılarına tabi tutularak rüzgâr yönü tespit edilmektedir. Sensörden alınan $0^{\circ}-360^{\circ}$ arasındaki değerler, $0^{\circ}-90^{\circ}$ (Kuzey), 90 ${ }^{\circ}-180^{\circ}$ (Doğu), $180^{\circ}-270^{\circ}$ (Güney) ve $270^{\circ}-360^{\circ}$ (Batı) olmak üzere 4 yön üzerinden ele alınmıştır (Kishorebabu ve Sravanthi, 2020). Örneğin; "Sensörden alınan açı değeri $326^{\circ}$ ise sonuç olarak Rüzgâr $=>$ Batı yönünde $\mathbf{5 6}^{\circ}$ 'lik açı ile esmektedir." ş̧eklinde bir örnek verilebilir.

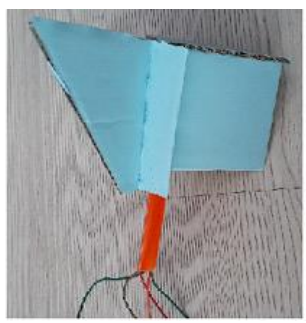

(a)

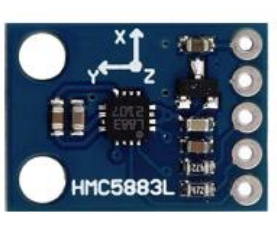

(b)

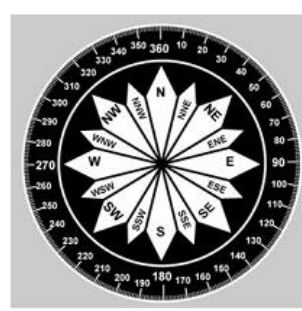

(c)
Şekil 4. a. Gerçekleştirilen Rüzgâr Yönü Sensörü, b. Pusula Sensörü, c. Rüzgâr Açıları

\subsection{Veri Tabanı Tasarımı}

Sensörlerden alınan hava durumu parametrelerinin saklanması, işlenmesi ve kontrol edilmesi amacıyla MySQL veri tabanı tasarımı yapılmıştır. Raspbian işletim sistemi içerisine kurulan MySQL server uygulaması üzerinden çalıştırılan MySQL veri tabanı ile verilerin yönetilmesi, saklanması ve izlenmesi sağlanmaktadır. Sensörlerden elde edilen sıcaklık, nem, basınç, yağmur, rüzgâr hızı, rüzgâr derecesi, rüzgâr yönü ve güncel zaman verileri kaydedilmek için veri tabanında bir tablo oluşturulmuştur. Sensörlerden elde edilen veriler, 5 sn. aralıklarla veri tabanına kaydedilmektedir. Şekil 5'de phpmyadmin uygulaması üzerindeki veri tabanı tablosuna kaydedilen sensör verileri verilmiştir. Veri tabanı içerisindeki 
hava durumu verileri, yazılan servis uygulamaları ile web tabanlı kullanıcı arayüzüne aktarılmaktadır.

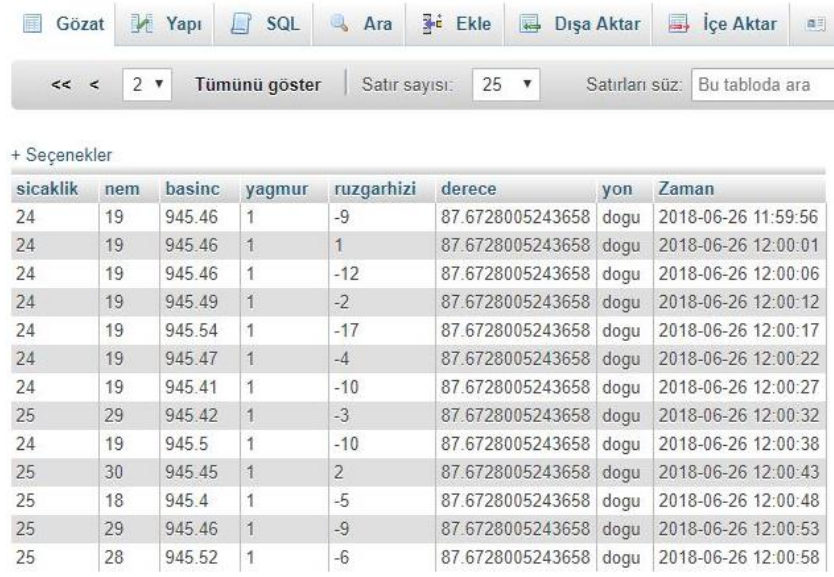

$\ll<2$ Tümünü göster | Satır sayıs: 25 V Satrları süz: Bu tabloda ara

Şekil 5. Veri Tabanındaki Sensör Verilerinin Gösterimi

\subsection{Gerçek Zamanlı Kullanıcı Arayüzü}

Çalışmanın temel amaçlarından bir tanesi olan hava durumu bilgilerinin izlenmesi işlemi için hazırlanan web arayüzü ile düzenli bir şekilde anlık olarak meteorolojik verilerin izlenmesi sağlanmıştır. Geliştirilen izleme sisteminde iki farklı kodlama süreci yaşanmıştır. İlk aşamada, sensörlerden elde edilen ham verilerin işlenmesi ile elde edilen değerlerin veri tabanına kaydedilmesi için Python programlama dili kullanılmıştır. İkinci aşamada ise web arayüzünde hava durumu bilgilerinin izlenmesi için php, html ve javascprict programlama dilleri kullanılmıştır. Web arayüzü için yazılan servis uygulamaları ile MySQL veri tabanı üzerinden her sensöre ait veriler teker teker alınmaktadır. Arayüz ile veri tabanı üzerindeki en son hava durumu bilgisine doğrudan erişim sağlanırken tüm verilere erişebilme imkânı da bulunmaktadır. $\mathrm{Bu}$ veriler, Highcharts interaktif javascript kütüphaneleri kullanılarak web arayüzü üzerinden grafiksel olarak kullanıcılara aktarılmaktadır. Hava durumu izleme istasyonunda alınan en son hava durumu verisi Şekil 6'da verilmiştir. İstasyon içerisindeki her parametre değeri için ayrı ayrı grafikler verilmektedir. Sensörlerden elde edilen verileri, 5 sn. aralıklarla güncellenerek sistemin sürekliliği devam ettirilmektedir.

\section{Hava Durumu İzleme İstasyonu}

○円

\begin{tabular}{|l|c|c|c|c|c|c|c|c|}
\hline Birimler & Tarih & Sıcaklık & Nem & Basınç & Yağmur & Rüzgar Hızı & Rüzgar Açısı & Rüzgar Yönü \\
\hline $\begin{array}{l}\text { Güncel } \\
\text { Değerler }\end{array}$ & $\begin{array}{c}2018-06-28 \\
15: 58: 21\end{array}$ & 23 & 19 & 940.52 & 1 & -63 & 66,81313 & $\begin{array}{c}\text { Kuzey } \\
\text { (North) }\end{array}$ \\
\hline
\end{tabular}

Tüm verilere ulaşmak için tıklayınız.

Şekil 6. Veri Tabanından Alınan Son Hava Durumu Bilgileri

\section{Hava İstasyonunun Çalıșma Yöntemi}

Hava durumunun izlenmesi amaciyla hazırlanan hava istasyonunun çalışma prensibi Şekil 7'de gösterilmiştir. Ortamdaki hava durumu verileri elde edilirken, rüzgâr hızı, rüzgâr yönü, sıcaklık, nem yağmur ve basınç sensörleri kullanılmıştır. Sensörlerden alınan analog ve dijital veriler, Raspberry Pi kartı ile işlenerek ortamdaki hava durumu ile ilgili parametre değerleri elde edilmiştir. Elde edilen veriler kullanıcılara aktarılması ve anlık olarak takip edilmesi amacıyla bir web arayüzü geliştirilmiştir. Geliştirilen web arayüzü aracılığıyla ortamdaki hava durumu bilgilerine erişim sağlanmakta ve ortam verilerinin değerleri (sıcaklık, nem, yağış, basınç, rüzgâr) grafiksel olarak gösterilmektedir. Web arayüzünde istasyon aracılığıyla alınan en son hava durumu bilgisi de kullanıcılara ayriyeten sunulmaktadır.

Rüzgâr hızı sensöründen alınan analog verilerin Raspberry Pi 3 kontrolcü kartı ile işlenmesi amacıyla ADC click kartı kullanılmıştır. Raspberry Pi 3 kartı içerisinde ADC birimi olmadığ 1 için bu kart tercih edilmiştir. ADC click kartı, analog değerleri dijital değerler dönüştürmektedir. Kart, SPI haberleşme protokolü üzerinden iletişim kurabilmekte ve içerisinde 4 adet ADC kanalı bulunmaktadır. Basınç ve rüzgâr yönü sensörleri I2C protokolü ile çalıştığı için aynı pinler üzerinden farklı adres bilgileri kontrol edilmektedir. Tablo 2'de Raspberry Pi 3 kartı ve sensörler arasındaki pin bağlantıları verilmiştir.
Tablo 2. Pin Bă̆lantılart

\begin{tabular}{c|c}
\hline Raspberry Pi 3 & Sensörler \\
\hline BCM 14 & DHT11 Sensörü \\
BCM 23 & Yağmur Sensörü \\
BCM 2 & Basınç Sensörü (SCL) \\
BCM 3 & Basınç Sensörü (SDA) \\
BCM 2 & Rüzgâr Yönü (SCL) \\
BCM 3 & Rüzgâr Yönü (SDA) \\
BCM 9 & (ADC Click) SDO \\
BCM 10 & (ADC Click) SDI \\
BCM 11 & (ADC Click) SCK \\
\hline
\end{tabular}

\subsection{Hava Durumu Tahmin Algoritması}

İstasyon içerisindeki sensörlerden alınan verilere göre hava durumuna ait çıkarımlar yapılmaktadır. Yapılan ölçüm sonuçları üzerinden karşılaştırmalar yapılarak bazı kurallar oluşturulmuştur. Örneğin; basınç, sıcaklık ve nem senöründen alınan veriler kullanılarak, "eğer sicaklık değeri $>30{ }^{\circ} \mathrm{C}$, nem değeri $>=75 \%$, basınç değeri $<1012 \mathrm{hPa}$ ise Hava Durumu: SICAK" şeklinde bir kural yazmak mümkün olabilmektedir. Yazılan kurallardaki eşik seviyeleri, ölçüm sonuçlarına göre güncellenmektedir. Kural sistemine yağmur sensörünün eklenmesi ile yağmurun durumunu ve şiddetini de ölçmek mümkün olabilmektedir. Farklı sensör aralıklarına ait kural çıkarım örneklerine ait kaba kod şekil 8'de verilmiştir. Tahmin algoritması şu aşamada kullanıcılara aktarılmayıp sadece test sürecinde kullanılmaktadır. 


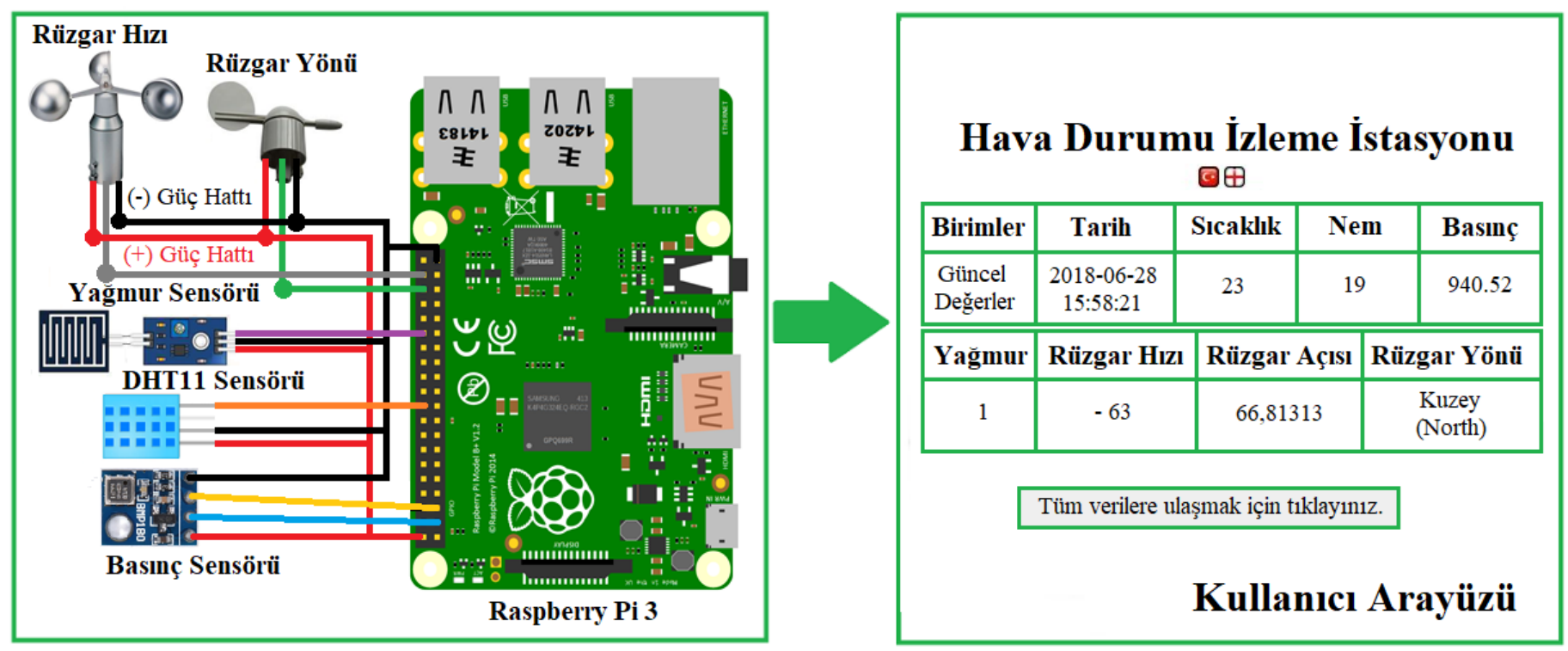

Şekil 7. Hava İstasyonu Sisteminin Çalışma Prensibi

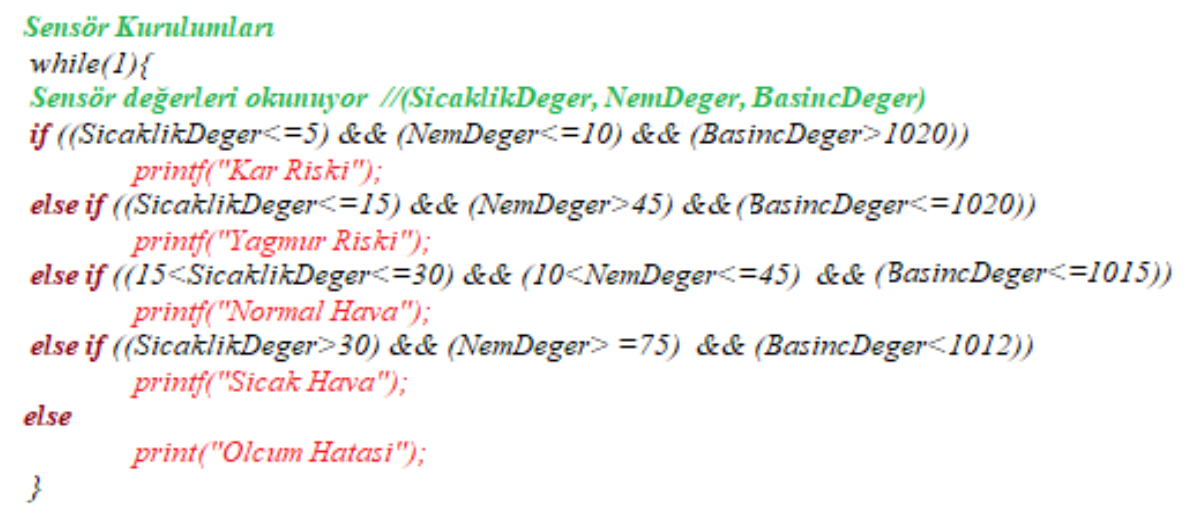

Şekil 8. Hava Durumu Tahmin Algoritmasının Kaba Kodu

\section{Hava İstasyonu Test Çalışmaları}

Raspberry Pi 3 kontrolcü kartı içerisindeki Python kodunun çalıştırılmasıyla, sensörlerden elde edilen ham verilerin ekran çıktısı Şekil 9'da gösterilmiştir. Hava istasyonu içerisindeki sensörlerden alınan değerler içerisinden sadece sıcaklık, nem, yağış, basınç, dijital dönüş değeri, rüzgâr açı değeri ve güncel zaman bilgileri veri tabanına kaydedilirken diğer veriler kullanılmamıştır.

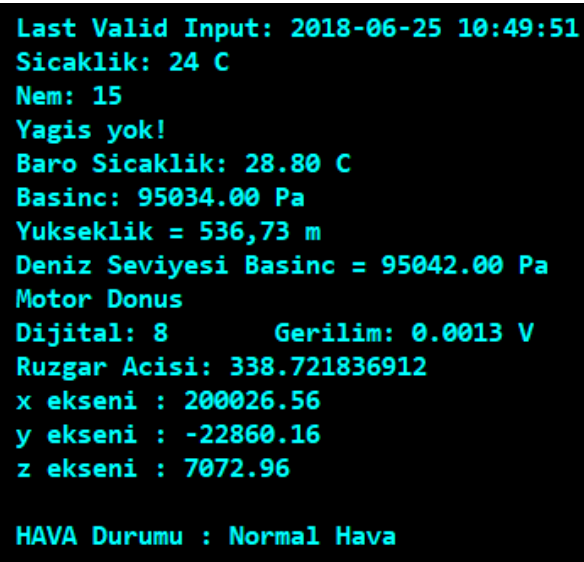

Şekil 9. Sensörlerden Elde Edilen Ham Veriler
Geliştirilen hava istasyonunun donanımsal görünümü Şekil 10'da verilmiştir. İstasyon, hava parametrelerinin hassas bir şekilde ölçülerek işlenmesini sağlamak amacıyla tasarlanmıştır. Raspberry Pi 3 kontrolcü kartı üzerinde bulunan GPIO pinleri aracılığıyla sensörler ve Raspberry pi kontrolcü kartı arasındaki bağlantılar gerçekleştirilmiştir. Geliştirilen hava istasyonundaki Raspberry pi 3 kontrolcü kartının internet ihtiyacını karşılama için kablolu internet, güç ihtiyacı için ise 5V'luk adaptör kullanılmıştır.

Donanımsal ve yazılımsal çalışmaların başarılı bir şekilde gerçekleştirilmesinden sonra laboratuvar ortamında hava durumu verilerinin toplanmasına başlanmıştır. Sıcaklık, nem, yağış, basınç ve rüzgâr parametrelerinin gerçek zamanlı olarak sensörler aracılığıyla toplanması gerçekleştirilmiştir. Elde edilen değerler, görselleştirmek amacıyla veri tabanına kaydedilmiş ve hazırlanan web arayüzü üzerinden kullanıcılara sunulmuştur.

Sensörlerden elde edilen ortam parametrelerine ait grafikler Şekil 11'da verilmiştir. Şekil 11'da sırasıyla, sıcaklık (a), nem (b), basınç (c), rüzgâr hızı (d), rüzgâr açısı (e) ve rüzgâr yönlerini gösteren grafikler gösterilmektedir. Grafikler, iteratif olarak hazırlanmıştır. Şekil11.a'da sıcaklık verileri, şekil 11.b'de nem verileri ve şekil 11.c'de basınç sensöründen elde edilen basınç değerleri gösterilmektedir. Sırasıyla alınan verilerin, iteratif bir şekilde gösterildiği grafiklerde belirli aralıklarda artışlar ve düşüşler yaşanmaktadır. 
Şekil 11.d'de rüzgâr hızı sensöründen alınan değerler gösterilmektedir. Şekildeki değerlere bakıldığında (-) ile ifade edilen değerler rüzgârın saat yönünün tersinde $(+)$ ile ifade edilen değerler ise rüzgârın saat yönünde estiğini göstermektedir. Elde edilen sayısal değerler ise rüzgâr şiddetini göstermektedir. Yapılan testler ve hesaplamalar ile bu sonuçlara ulaşılmıştır. Şekildeki verileri açıklamak gerekirse, örneğin; sensörden alınan değer -25 olarak verilsin, bu değer üzerinden rüzgârın saat yönünün tersinde ve 25 hızında estiği sonucuna varılabilir.

Şekil 11.e'da rüzgâr yönü ile ilgili açısal değerlere ait grafik gösterilmektedir. Hazırlanan rüzgâr hızı sensörü içerisinde bulunan pusula sensöründen elde edilen veriler yön ve derece hesaplama işlemlerine tabi tutularak rüzgârın açısı ve hangi yönde estiği görülmektedir. Sensörden alınan $0^{\circ}-360^{\circ}$ arasındaki açı değerleri, yönler (kuzey, güney, doğu ve batı) üzerinden hesaplama işlemine tabi tutulmaktadır. Bu hesaplama işlemi ile elde edilen sensör açısının hangi yöne denk geldiği tespit edilmiştir.

Sensörlerden alınan veriler, anlık olarak değişebildiği için grafiklerde belirli aralıklarda artışlar ve düşüşler yaşanmıştır. Sistemin düşük maliyetli olması, kolay kurulumu, mobil olarak rahatlıkla taşınması ve internet üzerinden kontrol edilmesi gibi avantajları sayesinde ek donanım ihtiyacına gerek duyulmaksızın bulunduğu ortamdaki hava durumunun anlık olarak takip edilmesi sağlanmaktadır.
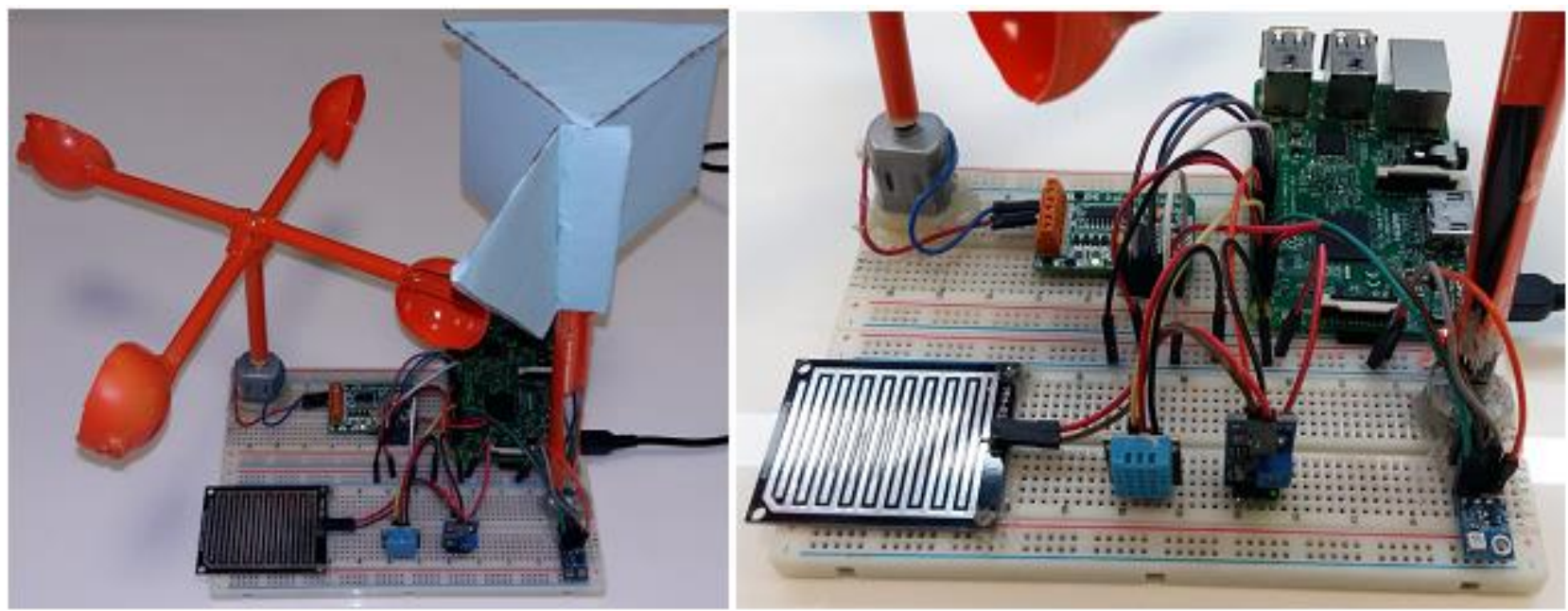

Şekil 10. Hava İstasyonunun Donanımsal Gösterimi

\section{Sonuç}

$\mathrm{Bu}$ çalışma kapsamında, web üzerinden anlık hava durumunun izlenmesine imkân sağlayan IoT tabanlı bir mini hava istasyonu gerçekleştirilmiştir. Çalışmanın temel amacı, okul ve üniversite gibi yerleşkelerdeki hava durumunun gerçek zamanlı olarak takip edilmesi ve kayıt altına alınmasıdır. Bu amaçla kullanılacak hava istasyonu içerisinde, Raspberry Pi 3 kontrolcü kartı, sıcaklık, nem, basınç, yağış, rüzgâr hızı ve rüzgâr yönü sensörleri kullanılarak sistemin tasarımı oluşturulmuştur. Hava durumu parametreleri Raspberry Pi 3 kontrolcü kartında işlendikten sonra Wi-Fi ağı üzerinden veri tabanına kaydedilmektedir. Veri tabanında çekilen hava durumu bilgileri, hazırlanan web ara yüzü üzerinden grafiksel ve sayısal olarak kullanıcılara sunulmaktadır. Hava durumu izleme istasyonu modeli, ekonomik, taşınabilir, kullanımı kolay ve küçük boyutlu olarak tasarlanmıştır.

Geliştirilen istasyonda hazır olarak kullanılan sensör ile birlikte özgün tasarıma rüzgâr yönü ve rüzgâr hızı sahip sensörleri de kullanılmıştır. Rüzgâr yönü sensörü içerisinde HMC5883L pusula sensörü bulunmaktadır. Pusula sensörü ile yapılan ölçümlerde yön bilgisi doğru bir şekilde elde edildikten sonra rüzgâr sensörünün çerçeve yapısı oluşturulmuştur. Yapılan çerçeve içerisine yerleştirilen pusula sensörü ile yapılan yeni yön testlerinde aynı başarımlar elde edilmiştir. Rüzgâr hızı sensörü içerisinde DC motor bulunmaktadır. DC motorun dönüşü sırasında meydana gelen hız verisi analog olarak okunmuş ve dönüş hızı belirlenmiştir. Rüzgâr hızı sensörünün çerçeve yapısı oluşturulduktan sonra dönüş testleri gerçekleştirilmiş ve bu yeni testlerin sonucunda aynı dönüş hızı değerleri elde edilmiştir. İlerleyen çalışmalarda modelleme teknolojisi kullanılarak daha efektif bir sensör gerçekleştirilecektir. Bu koşullar ele alınıp gerçekleştirilen çalışma, (Hussein ve ark., 2020; Baste ve Dighe, 2017)' daki sistemler ile karşılaştırıldığında donanımsal maliyetin belirtilen çalışmalardan daha düşük olduğu görülmektedir.

Çalışma kapsamında düşük maliyetli sensörlerin kullanılması ve bazı kalibrasyon sorunlarının meydana gelmesinden ötürü hesaplamalarda yanlışlıklar meydana gelmiştir. Bu durum, hatalara sebebiyet vermekte ve sistemin güvenilirliğini düşürmektedir. Bu sorunların üstesinden gelmek için donanımsal ve yazılımsal kaynakların optimum şekilde yapılandırılması sağlanmıştır. Buna rağmen nem ve rüzgâr hızı verilerinde hatalar meydana gelmiştir. Sistemin geliştirilmesi esnasında kullanılması düşünülen ek sensörler ile bu sorunun çözümü aranacak ve bu sayede sistemin dayanıklılığ artırılacaktır.

İstasyon ile yapılan test çalışmaları ilk olarak laboratuvar ortamında gerçekleştirilmiş olup sensör değerlerinin doğrulukları ölçülmüştür. Test işlemlerinden sonra dış ortada test işlemi gerçekleştirilerek, hava istasyonunun geçerliliği test edilmiştir. Tablo 3'de 25.05.2018 ve Tablo 4'de 26.05.2018 tarihlerinde yapılan ölçüm sonuçları verilmiştir. Sıcaklık, basınç ve rüzgâr yönü parametrelerinin değerlerinin yakın olmasına rağmen nem ve rüzgâr hızı değerlerinde belirli miktarlarda sapmalar yaşanmıştır. 


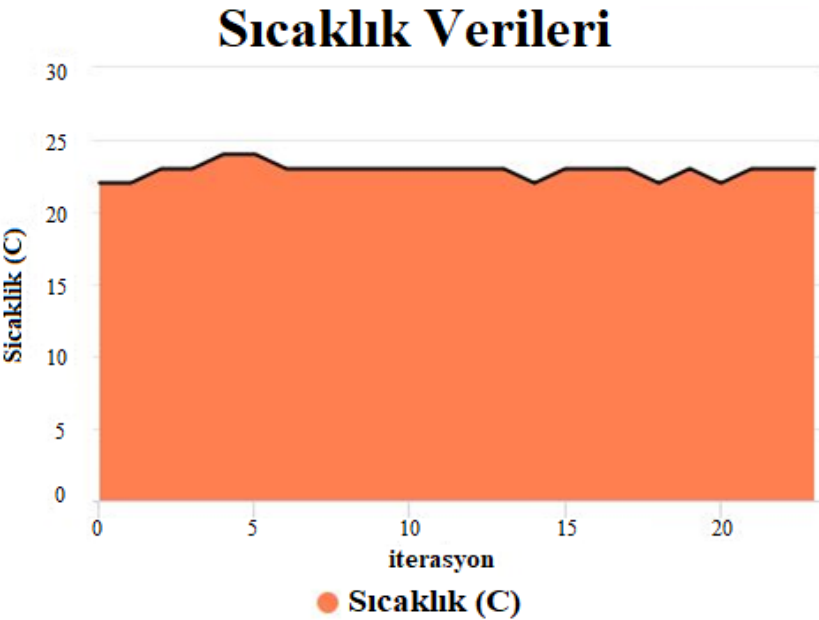

(a)

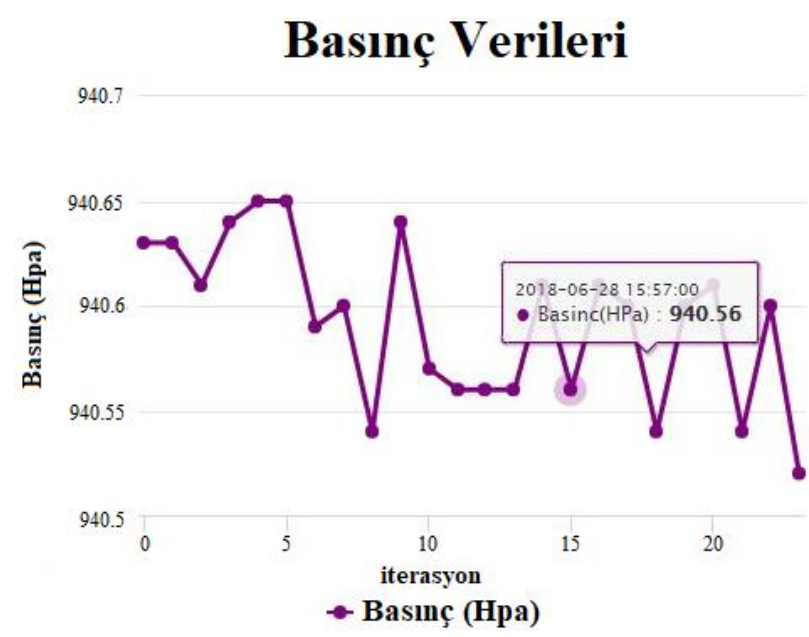

(c)

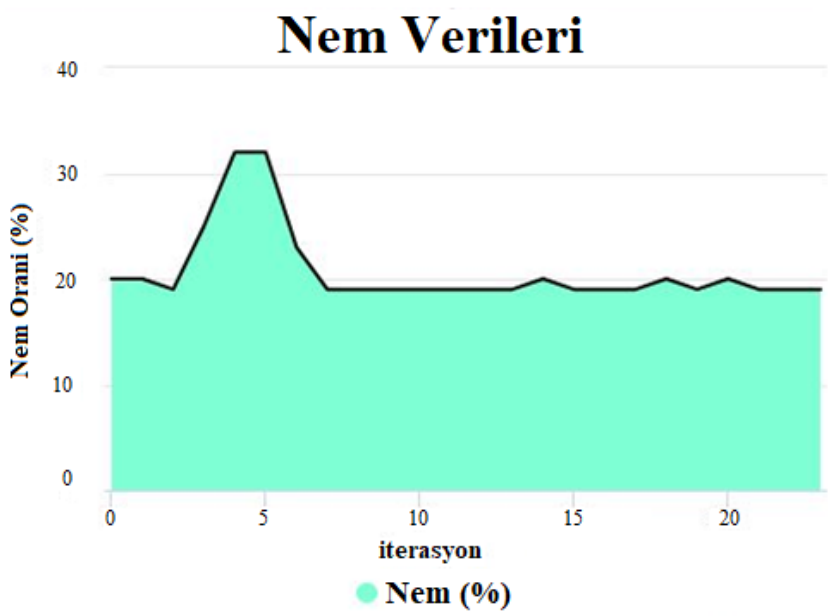

(b)

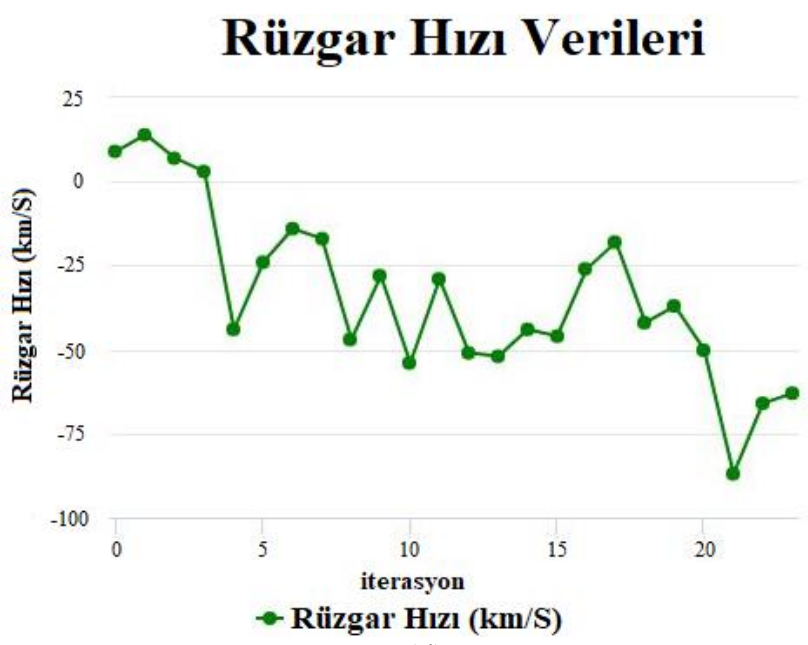

(d)

\section{Rüzgar Açısı Verileri}

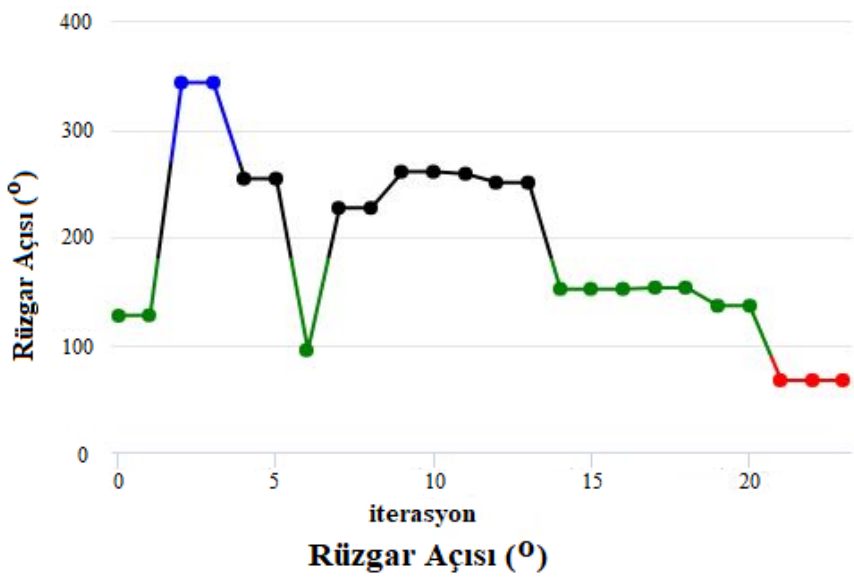

(e)

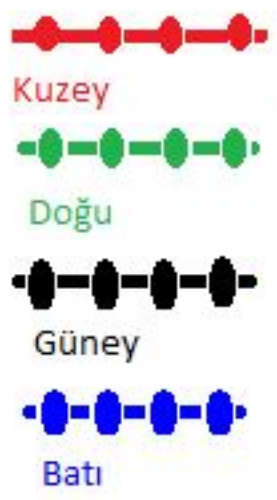

(f)

Şekil 11. Sensör Verilerinin Grafiksel Gösterimi

(a) Sıcaklık, (b) Nem, (c) Basınç, (d) Rüzgâr Hızı, (e) Rüzgâr Açısı, (f) Rüzgâr Yönleri

\begin{tabular}{c|c|c|c|c|c}
\multicolumn{7}{c}{ Tablo 3. 25.05.2018 Günü Yapılan Sensör Ölçümleri } \\
\cline { 2 - 6 } & Sensör Sonuçları \\
\cline { 2 - 6 } & Sı̈lı̈k & Nem & Basınç & Rüzgâr Hızı & Rüzgâr Yönü \\
\hline $\begin{array}{c}\text { Meteoroloji } \\
\text { Hava İstasyonu }\end{array}$ & $17,4^{\circ} \mathrm{C}$ & $\% 87$ & $947,6 \mathrm{hPa}$ & $4 \mathrm{~km} / \mathrm{S}$ & Güney Doğu \\
\cline { 2 - 6 } & $16^{\circ} \mathrm{C}$ & $\% 50$ & $950,28 \mathrm{hPa}$ & $9 \mathrm{~km} / \mathrm{S}$ & Güney Doğu \\
\hline
\end{tabular}


Tablo 4. 26.05.2018 Günü Yapılan Sensör Ölçümleri

\begin{tabular}{c|c|c|c|c|c}
\cline { 2 - 6 } & \multicolumn{5}{c}{ Sensör Sonuçları } \\
\cline { 2 - 6 } Meteoroloji & $23,7^{\circ} \mathrm{C}$ & $\% 54$ & $949,6 \mathrm{hPa}$ & Rüzgâr Hızı & Rüzgâr Yönü \\
\hline Hava İstasyonu & $24^{\circ} \mathrm{C}$ & $\% 24$ & $950,52 \mathrm{hPa}$ & $11 \mathrm{~km} / \mathrm{S}$ & Güney \\
\hline
\end{tabular}

İlerleyen çalışmalarda, sensör ve internet teknolojilerinin geliştirilmesi ile daha güvenilir ve hızlı çözümler sunabilecek bir hava istasyonu gerçekleştirilmesi hedeflenmektedir. İstasyona entegre edilmesi düşünülen yenilenebilir enerji kaynakları ile enerji ihtiyacının karşılanması sağlanacaktır. Temel amaç doğrultusunda kullanıma uygun olmasına rağmen daha geniş alanlarda hava olaylarını takip etmek için GPS sensörü kullanılarak farklı yerlerdeki hava durumu bilgileri elde edilecektir. Daha geniş bir akıllı çevre izleme sisteminin gerçekleştirilmesi ve hava durumunun tahmininde yapay zekâ teknolojilerinin kullanılmasına yönelik çalışmalar hedeflenmektedir.

\section{Kaynakça}

Aponte-Roa, D. A., Montalvan, L. B., Velazquez, C., Espinoza, A. A., Velazquez, L. F., Serrano, R, 2018. Evaluation of a low-cost, solar-powered weather station for small-scale wind farm site selection. IEEE International Instrumentation and Measurement Technology Conference (I2MTC), 14-17 May, Houston, TX, USA, 1-5.

Barkunan, S.R., Bhanumathi, V., Sethuram, J., 2019. Smart sensor for automatic drip irrigation system for paddy cultivation. Computers and Electrical Engineering, 73, 180193.

Baste, P., Dighe, D.D., 2017. Low Cost Weather Monitoring Station Using Raspberry Pi. International Research Journal of Engineering and Technology (IRJET), 4 (5), 3184-3189.

Devaraju, J.T., Suhas, K.R., Mohana, H.K., Vijaykumar A.P., 2015. Wireless Portable Microcontroller based Weather Monitoring Station. Measurement, 76 (2015), 189-200.

Divya, M., Subhash, N., Vishnu, P., Tejesh, P., 2020. Smart Health Care Monitoring Based on Internet of Things (IoT). International Journal of Scientific Research and Engineering Development, 3 (1), 409-414.

Eriş, Ç., Bölük, P. 2021. Nesnelerin İnternetinde Kullanılan Kablosuz Algılayıcı Cihazlar için Bilgi Merkezli Ağ Mimarisinin Uygulanabilirliği Araştırması. Avrupa Bilim ve Teknoloji Dergisi, (21), 160-171.

Fente, D.N., Singh, D.K., 2018. Weather Forecasting Using Artificial Neural Network. 2nd International Conference on Inventive Communication and Computational Technologies (ICICCT 2018), 20-21 April, Coimbatore, India, 1757-1761.

Haque, M. I., Shatil, A.H.MD., Tusar, A.N., Hossain, M., Rahman, M. H., 2019. Renewable Powered Portable Weather Update Station. 2019 International Conference on Robotics, Electrical and Signal Processing Techniques (ICREST), 10-12 January, Dhaka, Bangladesh, 374-377.

Hussein, Z.K., Hadi, J.H., Abdul-Mutaleb, M.R., Mezaal, Y.Z., 2020. Low cost smart weather station using Arduino and ZigBee. TELKOMNIKA Telecommunication, Computing, Electronics and Control, 18 (1), 282-288.

Katyal, A., Yadav, R., Pandey, M., 2016. Wireless Arduino Based Weather Station. International Journal of Advanced Research in Computer and Communication Engineering, 5 (4), 274-276.
Kishorebabu, V., Sravanthi, R., 2020. Real Time Monitoring of Environmental Parameters Using IOT. Wireless Personal Communications, 1-24, https://doi.org/10.1007/s11277-02007074-y.

Kusriyanto, M., Putra, A.A., 2018. Weather Station Design Using IoT Platform Based On Arduino Mega. International Symposium on Electronics and Smart Devices (ISESD), 2324 October, Bandung, Indonesia, 1-4.

Li, H., Ochani, M.K., Zhang, H., Zhang, L., 2017. Design of micro-automatic weather station for modern power grid based on STM32. The Journal of Engineering, 2017 (13), 1629-1634.

Mahbub, M., 2020. A smart farming concept based on smart embedded electronics, internet of things and wireless sensor network. Internet of Things, 9, 100161.

Muck, P.Y., Homam, M.J., 2018. Iot Based Weather Station Using Raspberry Pi 3. International Journal of Engineering \& Technology, 7 (2018), 145-148.

Nsabagwa, M., Byamukama, M., Kondela, E., Otim, J.S., 2019. Towards a robust and affordable Automatic Weather Station. Development Engineering, 4, 1-9

Ram K.S.S, Gupta, A.N.P.S., 2016. IoT based Data Logger System for weather monitoring using Wireless sensor networks. International Journal of Engineering Trends and Technology (IJETT), 32 (2), 71-76.

Saglam, A., Taş, M., Baykan, N.A. 2020. Geri Dönüştürülebilir Atıkların Materyallerine Göre Sınıflandırılması için Raspberry Pi Tabanlı Donanım Geliştirilmesi. Avrupa Bilim ve Teknoloji Dergisi, (Özel Sayı), 30-38.

Saini, H., Thakur, A., Ahuja, S., Sabharwal, N. \& Kumar, N., 2016. Arduino Based Automatic Wireless Weather Station with Remote Graphical Application and Alerts. 3rd International Conference on Signal Processing and Integrated Networks (SPIN), 11-12 February, Noida, India, 605-609.

Utama, Y.A.K., Widianto, Y., Sardjono, A.T., Kusuma, H., 2018. Design A Low Cost Wind Direction Sensor With High Accuracy. 5th International Conference on Information Technology, Computer, and Electrical Engineering (ICITACEE), 27-28 September, Semarang, Indonesia, 3338.

Üçgün, H., Kaplan, Z.K., 2017. Arduino based weather forecasting station. International Conference on Computer Science and Engineering (UBMK), 5-8 October, Antalya, Turkey. 